\title{
El tratamiento audiovisual de los menores de edad en los filmes que recrean el contexto de la dictadura franquista. Estudio del cine español realizado durante la etapa democrática (1978-2015)
}

\author{
Adingabeen ikus-entzunezko tratamendua frankismoaren diktaduraren \\ testuingurua azaltzen duten filmetan. Etapa demokratikoan zehar \\ (1978-2015) egindako zinema espainiarraren ikerketa
}

Audiovisual treatment of underage in films that recreate the context of the Franco dictatorship. Study of Spanish cinema in democratic period (1978-2015)

\author{
María Nieves Corral Rey* \\ Universidad de Málaga/Escuela Autónoma de Dirección de Empresas (Málaga)
}

RESUMEN: La atención del presente estudio se ha centrado en el análisis del tratamiento audiovisual del personaje menor de edad como protagonista integrado en filmes españoles realizados durante la etapa democrática (1978-2015) e inspirados en el contexto de la dictadura franquista. Para su exploración se ha elaborado una ficha que recoge tres dimensiones: fisica, psicológica y sociológica. La metodología utilizada ha sido el estudio filmico, enmarcado en el análisis de contenido, y la muestra la integran trece filmes que responden a las características anteriormente descritas. Las principales conclusiones apuntan a la presencia de una serie de metáforas relevantes, que desarrollan un hilo narrativo en estos personajes, así como la omisión de sus raíces familiares.

PALABRAS CLAVE: Cine español, franquismo, infancia, adolescencia, análisis de contenido, transición.

ABSTRACT: Focus of this study has been audiovisual treatment underage character as main role integrated in spanish films realized in the democratic period (1978-2015) and inspired by the context of the Franco dictatorship. For his exploration, we have elaborated a study sheet that covers three dimensions: physical, psychological and sociological. Methodology used has been film analysis, framed in content analysis, and the sample is made up of thirteen films corresponding to the characteristics mentioned above. In addition, we has been observed some narrative points of connection and we have explorated psychology of the characters. Conclusions point to the presence of a series of relevant metaphors, which develop a narrative thread in these characters, as well as the omission of their family roots.

KEYWORDS: Spanish cinema, Franco dictatorship, infancy, adolescence, content analysis, transition.

\footnotetext{
* Correspondencia a / Corresponding author:: María Nieves Corral Rey. Universidad de Málaga. Escuela Autónoma de Dirección de Empresas (EADE), c/ Fernández shaw 88, 29017 Málaga - nievescorral@eade.es - https ://orcid. org/0000-0002-3365-097x

Cómo citar / How to cite: Corral Rey, María Nieves (2019). "El tratamiento audiovisual de los menores de edad en los filmes que recrean el contexto de la dictadura franquista. Estudio del cine español realizado durante la etapa democrática (1978-2015)»; Zer, 24(46), 147-164. (https://doi.org/10.1387/zer.20402).
}

Recibido: 20 noviembre, 2018; Aceptado: 29 abril, 2019.

ISSN 1137-1102 - elSSN 1989-631X / (C) 2019 UPV/EHU

(c) (i) Esta obra está bajo una licencia 


\section{Introducción}

El presente manuscrito recoge una síntesis de la investigación llevada a cabo en el marco de la tesis doctoral desarrollada en una temporalidad de tres años en el Programa de Doctorado Interuniversitario en Comunicación de la Universidad de Málaga. Y nace del deseo de estudiar el tratamiento audiovisual de los niños y de los adolescentes en el medio filmico, con el fin de explorar una serie de cuestiones del contenido y de la sintaxis de las películas españolas realizadas desde 1978 hasta 2015, cuyo contexto socio histórico se inspira en el período de la dictadura franquista (1939-1975) y los primeros años de la Transición política española (1975-1978).

En líneas generales, el objeto de estudio es el cine español. Especialmente la representación de los personajes menores de edad, es decir, aquellos individuos masculinos y femeninos cuya edad está comprendida entre los 0 y 17 años, que participan como protagonistas o tienen otro papel relevante desde el punto de vista diegético en las producciones anteriormente especificadas. Se ha delimitado la muestra del estudio de casos a la ficción cinematográfica de largometrajes, pues se busca analizar la recreación imaginaria principalmente de situaciones de represión y de exaltación de valores del nacional catolicismo presentes durante la dictadura franquista en los entornos que rodean a los menores de edad. En este sentido, nos interesa especialmente cómo los directores de cine entienden y reflejan las acciones llevadas a cabo por éstos y las consecuencias derivadas de las actuaciones de los adultos en el universo de infantil y adolescente. Tomando como referencia su imaginación y su interpretación de los acontecimientos acaecidos en nuestra historia reciente.

Realmente el motivo que nos ha conducido a elegir una serie de producciones realizadas a partir de 1978, pero que toman como referencia el período de la dictadura, viene de la mano del texto fundamental que contribuyó a la desaparición de la censura previa: el Real Decreto-Ley 24/1977 de 1 de abril. Precisamente esta normativa permitió la articulación de discursos más directos y el desarrollo de géneros hasta el momento casi ausentes del panorama audiovisual español (De Felipe y Gómez, 2012).

Respecto a esta cuestión, conviene matizar que se toma como punto de partida la producción cinematográfica española desde los comienzos de la Democracia porque se toma como referencia el contexto político, social y cultural que se inicia a raíz de las primeras elecciones democráticas (1977), después de la etapa de la dictadura. Y es a partir de 1978 cuando se proclama la Constitución Española. Asimismo, el mencionado Real Decreto-Ley 24/1977 marca, sin duda, un punto de inflexión para la industria cinematográfica en nuestro país que, desde luego, tiene una profunda repercusión en el plano social y cultural. En aras de poder contemplar las particularidades de nuestro objeto de estudio durante toda la etapa democrática, el análisis que aquí se plantea abarca las producciones realizadas desde 1978 hasta 2015. 
Por otro lado, en este caso consideramos el cine como texto, al igual que defendía Christian Metz (1972). No se ahondarán en las bases de sus teorías, ya que no forma parte de los objetivos de esta investigación, pero se aplicarán sus consideraciones referidas a la lectura de las imágenes a través de la concepción código-mensaje. Desde luego, la naturaleza de esta investigación hace que se haya abordado metodológicamente desde la perspectiva de los análisis clásicos de los estudios filmicos que relacionan la sintaxis cinematográfica con el estudio de contenido, englobado en una metodología cualitativa, que tiene como bases las tareas de observación, de análisis y de descripción de los datos que aporta la imagen filmica. De este modo, desentrañar una serie de elementos del discurso filmico que puedan pasar desapercibidos, pero entendidos como posibles simbolismos. Así pues, el propósito no consiste en suministrar respuestas irrefutables ni conseguir establecer una verdad absoluta de cada película, sino en ofrecer una serie de interpretaciones de determinados elementos de los textos audiovisuales, que no son únicas y están sometidas a las valoraciones, las críticas y las apreciaciones. Con el fin de articular un perfil de tratamiento de la infancia en distintos contextos en el cine, y específicamente, en uno de los entornos represivos y de violencia que tanto duele mirar al público, como es esta etapa correspondiente a nuestro pasado más cercano que continúa punzando en nuestro presente por el dolor que lleva consigo el acto de recordarla.

Además del mencionado objetivo principal, se han perseguido otros objetivos complementarios, entre los cuales podemos destacar: 1) Investigar sobre la base de la fundamentación y los aspectos que se tienen en cuenta en la construcción de las características de los personajes. 2) Y comparar los elementos de la construcción de la dimensión psicológica de los menores de edad en el conjunto de las películas estudiadas, atendiendo a factores como el temperamento, el carácter y la personalidad.

En definitiva, se estudiará el cine que recrea este período de posguerra y dictadura de nuestro país, porque, de acuerdo con Pantoja Chaves (2011) el franquismo sugiere un cruce de miradas, entre las cuales se pueden destacar: una visión sobre la necesidad de forjar el recuerdo del pasado franquista y otra ligada a una generación que promueve la recuperación de la memoria.

\section{Los menores de edad en el medio fílmico}

Resulta de interés acometer la labor de examinar cómo se representan en la ficción cinematográfica las estrategias de supervivencia de aquellos menores, en su tentativa de salvaguardar su integridad fisica y psicológica (Yela Fernández, 2013). Junto a la representación ficticia de sus intentos de buscar la felicidad y evasión de medidas represivas o violentas en este contexto en el cual les tocó vivir, pues se ha encontrado una ausencia de investigaciones centradas en la exploración de la construcción de su dimensión psicológica y las estrategias audiovisuales con las cuales se recrea su universo 
en este contexto. Acometiéndose, principalmente, desde una perspectiva histórica más que cinematográfica. En este sentido, compartimos la consideración de que la mirada de la infancia ha resultado ser uno de los lugares más elegidos desde donde relatar y reescribir un contexto histórico de nuestro pasado que sigue siendo objeto de discusiones (Gómez López-Quiñones, 2009). Tampoco se puede obviar que la presencia de individuos infantiles y adolescentes en el medio cinematográfico genera una serie de emociones. En especial, cuando los menores se presentan en contextos de sangre y de violencia, por las huellas que dejan en su dimensión mental y, como consecuencia, se produce una reacción afectiva en el espectador (Zumalde Arregui, 2011).

A la infancia y a la adolescencia representada en el medio filmico que recrea este periodo histórico de nuestro país no se le ha otorgado una atención propia desde el ámbito científico. Precisamente se revela como un medio de reflexión sobre su sufrimiento representado en la gran pantalla, frente a lo que supuso uno de los grandes dramas de nuestra historia más reciente: una larga dictadura que los marcó psicológicamente como jóvenes y futuros adultos. Ciertamente, estos años fueron dolorosos para la sociedad en general, pero sobre todo estimamos que para los menores de edad, ya que su mente frágil es más vulnerable y manipulable por el universo compuesto por los adultos.

Aunque, en líneas generales, dramas similares padecidos por los niños y los adolescentes en distintos conflictos han sido llevado a las pantallas por multitud de producciones cinematográficas de distinta nacionalidad (Ocón Domingo, 2006). No cabe duda que, durante la etapa de la infancia, los episodios de abuso resultan espeluznantes: se trate de maltrato, de abandono, de acoso, de conflictos bélicos, de explotación, de violación y de discriminación, como resultado de legislaciones abusivas, costumbres sociales inhumanas y sanguinarias que conducen a una serie de actuaciones deleznables, que aún siguen vigentes en diferentes puntos geográficos. Ello hace de los menores de edad un grupo social más delicado ante al universo adulto. Sin embargo, a la hora de acometer un análisis centrado en la representación de los menores de edad «resultaría erróneo referirnos a la infancia o a la mirada del niño como si fuesen realidades naturales, y como si sus características formales y sus elementos constitutivos careciesen de una historia» (Gómez López-Quiñones, 2009: 73), pues constituyen importantes referencias para recapacitar sobre cómo esas infancias fueron manipuladas y violentadas.

\section{Metodología}

\subsection{HiPÓTESIS}

De forma previa al desarrollo de este estudio, se han planteado una serie de hipótesis que trataremos de dilucidar a lo largo de la investigación. En la primera de 
ellas se expone que la narrativa cinematográfica española realizada durante la etapa democrática que toma como referencia el contexto de la dictadura franquista, los niños y los adolescentes se representan ambientados en entornos autoritarios y represivos, en los cuales la violencia adquiere especial relevancia precisamente con el fin de la dominación de los individuos. Si bien, resulta objeto de análisis la función o el porqué del uso de esta violencia dirigida hacia los menores de edad.

Por otro lado, se plantea que en el cine español realizado durante la democracia e inspirado en este contexto de dictadura los adultos causan perjuicios en la inocencia de los pequeños haciendo uso del odio, el miedo, la intolerancia, la ruptura de los sueños y las ilusiones. Por consiguiente, la caracterización de los personajes infantiles y adolescentes queda condicionada tanto por el contexto como por la construcción de los rasgos de dimensión psicológica de los propios adultos que los rodean.

En tercer lugar, se afirma que través de los códigos del lenguaje audiovisual se consigue representar a los menores de edad en las producciones que son objeto de este estudio de una forma más compleja. Mientras que con los adultos se recurre a estereotipos sociales, con el objetivo de ser reconocidos por el espectador en su postura ideológica.

\subsection{Fundamentación Metodológica}

No se puede obviar que este estudio se enmarca en la rama de las Ciencias Sociales y Humanas, en las cuales las metodologías de estudio no son exactas, ya que la investigación social está sometida a una serie de variables subjetivas. En cambio, las Ciencias Naturales o de la Salud se rigen por la precisión y la objetividad (Lincoln y Guba, 1985). Será por ello por lo que estas disciplinas de investigación se encuentran alejadas del mundo empresarial y han sido acusadas de no contar con una metodología concreta como una disciplina científica. Desde luego, los estudios en este ámbito se encuentran más bien relacionados con un análisis hermenéutico que con una certificación exacta (Perceval y Fornieles Alcaraz, 2008). Así pues, se aclara nuevamente que el presente estudio se plantea tomando como referencia un tipo de investigación cualitativa, que implica gran rigurosidad y se fundamenta en una recogida de información de datos, que emergen de una descripción pormenorizada y detallada a nivel de observabilidad (Anguera Argilaga, 1986).

El diseño metodológico se constituye en forma de una ficha de análisis, con la cual se irán desgranando una serie de aspectos más significativos, pero sin incluir, obviamente, juicios de valor. En particular, el objeto principal de este estudio es el cine y, precisamente esta materia compuesta por la imagen y el sonido está condicionada por las técnicas y las estrategias audiovisuales, las cuales se constituyen como formas de escribir los filmes (Martí Saldes, 2004). 
En primer lugar, durante la elaboración del marco teórico se ha llevado a cabo una revisión bibliográfica y lectura de literatura científica sobre las diferentes áreas en las cuales se enmarca el presente trabajo, principalmente la Cinematografía y la Crítica histórica. Una revisión en la cual se han tenido en consideración distintas aportaciones que integran las disciplinas abordadas, que iría de lo más general a lo particular: las características del contexto socio-histórico objeto de estudio; la importancia de la Memoria Histórica; un breve recorrido por el cine español realizado durante el período de la Transición Política y los primeros años de la Democracia; el concepto de la categoría social de la infancia y de la adolescencia y, en líneas generales, un somero recorrido por su proceso de aprendizaje; las relaciones entre el Cine y la Historia; el ejercicio de análisis fílmico, y, en particular, la creación y la construcción de personajes, así como las variables que intervienen en su estudio. Una revisión bibliográfica y un plan de trabajo que se revelan exhaustivos y, en lugar de citar referentes de peso de forma detallada en estas líneas, se invita a consultar la investigación de forma más pormenorizada cuando la tesis doctoral se encuentre en dominio público, pues temporalmente se encuentra embargada por contener resultados pendientes de publicación.

En segundo lugar, se ha explorado toda la filmografía de cine español desde 1978 hasta 2015, tomando como referencia el trabajo desarrollado por Asenjo García (1998). En esta obra se mencionan proyectos cinematográficos que, en su momento de edición, se encontraban en realización, pero no llegaron a culminar. Contiene entradas de unos 1.500 directores, los cuales no todos son españoles, pero las películas aquí mencionadas, al ser rodadas en España, adquieren consideración de Cine español. Por tanto, se han tenido en cuenta para la búsqueda y selección, actualizada con fecha de 2015 a través de otras fuentes, principalmente la base de datos de la Filmoteca Nacional. También se han consultado algunos otros portales de Cinematografia, pero existen multitud de errores en cuanto a la fecha de realización de las películas. Problema que ha ocasionado varios desórdenes durante este proceso de búsqueda y selección, ya que, como se indicó anteriormente, la fecha de partida toma producciones realizadas a partir de 1978. Aunque, en varias bases de datos algunas películas aparecen inscritas en este año por confusión con la fecha de estreno, pese a registrar su realización en la Filmoteca Nacional con anterioridad. Con todo, se ha optado por la fecha de inscripción en la página oficial del Ministerio de Cultura. Igualmente se han advertido algunos errores en multitud de bases de datos en cuanto a la delimitación de estas producciones, pues a la hora de su categorización se catalogan en el marco de la Guerra Civil películas que claramente describen en su inicio que se inspiran en la dictadura franquista y viceversa. Ello ha dificultado bastante el proceso de búsqueda de filmes.

Una vez recopilada y actualizada la filmografia hasta 2015, se ha ido indagando por los argumentos de los filmes para averiguar si se ajustan a los criterios estableci- 
dos en la investigación. No obstante, se ha descubierto que algunas películas se encuentran descatalogadas. Además, en cuanto a los principios de búsqueda propuestos, se busca que se ajusten a los siguientes criterios: filmes realizados a partir de 1978, protagonizados por individuos menores de edad (entre 0 y 17 años) y que estén incluidos en situaciones de represión y sometidos a la educación fundamentada en los principios del nacional catolicismo, que tuvieron un fuerte peso durante el contexto de la dictadura franquista. En este sentido, realmente no se han encontrado gran cantidad, de manera que no se ha podido establecer un número de producciones entre las que escoger para conformar la muestra del estudio empírico, sino que directamente se han seleccionado aquellas que se han podido ubicar ${ }^{1}$. Así pues, tras la búsqueda llevada a cabo, la muestra queda constituida por las siguientes producciones, junto a las cuales se señalan los nombres de los individuos en cuya figura se ha centrado la investigación:

- ¡Arriba Hazaña! (José María Gutiérrez Santos, 1978): grupo de alumnos internos.

- Demonios en el jardín (Manuel Gutiérrez Aragón, 1982): Juanito.

- Los años oscuros (Arantxa Lazcano, 1993): Itziar.

- Las ratas (Antonio Giménez-Rico, 1997): Nini.

- Gracias por la propina (Francesc Bellmunt, 1997): Ferrán y Pepín.

- El portero (Gonzalo Suárez, 2000): Tito.

- El florido pensil (Juan José Porto, 2002): Andrés.

- Eres mi héroe (Antonio Cuadri, 2003): Ramón.

- Silencio roto (Montxo Armendáriz, 2004): Juan.

- El laberinto del Fauno (Guillermo del Toro, 2006): Ofelia.

- Los girasoles ciegos (José Luís Cuerda, 2008): Lorenzo.

- Pa negre (Agustí Villaronga, 2010): Andreu.

- Pájaros de papel (Emilio Aragón, 2010): Miguel.

En este sentido, resulta pertinente comentar que según la consideración de distintos autores no existe un tamaño ideal de muestra en un estudio, pero las escasas producciones cinematográficas existentes han condicionado la búsqueda. No obstante, uno de los problemas que surge en la investigación en las áreas de Humanidades y Ciencias Sociales es la representatividad de la población seleccionada (Martínez-Salgado, 2012). Ahora bien, para el presente estudio resulta un universo notable, ante el definido elemento de estudio que se pretende explorar: el personaje menor de edad con papel protagonista o relevante en la narrativa cinematográfica española descrita anteriormente.

1 Solo se ha tenido que descartar el film titulado Estrellas que alcanzar (Mikel Rueda, 2010) porque la sinopsis suscitaba ciertas dudas para su inclusión en la muestra y aparte se trata de una película descatalogada, por lo que ha estado fuera de nuestro alcance. 
Asimismo, se ha revelado significativa la incorporación de algunas entrevistas a directores de cine, con la intención de indagar por sus consideraciones y descubrir sus estrategias de trabajo con los niños y adolescentes. Se ha abierto el arco a diferentes directores, pero existen numerosos cineastas que trabajan con menores de edad en diferentes puntos geográficos y esta tarea está condicionada fundamentalmente por la dificultad de sus compromisos sociales y otra serie de cuestiones incontrolables. Por tanto, nos hemos decantado por el contacto con los directores de las producciones que conforman nuestra muestra, a los se ha intentado acceder a través de su página web personal en algunos casos, la de sus productoras y también a través de la Academia de Cine. Institución que nos comunicó la imposibilidad de facilitar información privada como consecuencia de la aplicación de la Ley Orgánica de Protección de Datos, pero les enviarían nuestra información y ellos mismos contactarían con nosotros. Precisamente esta tarea ha resultado favorable con la voluntad de colaboración de Antonio Cuadri y Antonio Giménez-Rico. Por tanto, la presente investigación se ha nutrido de su trabajo práctico, de sus estrategias, de su tarea de construcción de personajes infantiles, de sus consideraciones sobre la legislación laboral en relación a esta etapa infantil y adolescente. Además de sus motivos para desarrollar producciones cinematográficas que se inspiran en el contexto socio histórico de este extracto del pasado de nuestro país.

\subsection{Diseño Metodológico Del ESTUdio EMpírico}

En este campo de las metodologías de análisis filmico encontramos múltiples propuestas. No obstante, no existe un método objetivo, universal e irrefutable, pues cada analista tiene su propio método (Aumont y Marie, 1990). En este sentido, también resulta indispensable tener en cuenta la afirmación de Nietzsche, cuando defendía que un texto permite distintas interpretaciones. Realmente un principio básico para entender los mecanismos que rigen las relaciones entre los seres humanos, por la necesidad de interpretar y con la dificultad de otorgar una exactitud precisa en lo que a connotaciones se refiere.

En lo que a construcción de personajes se refiere, efectivamente en distintos modelos de caracterización se suele apreciar un esquema análogo, construido alrededor de tres ejes: la descripción fisica, la descripción psicológica y la descripción sociológica. Aunque diferentes autores plantean distintos matices a incluir en cada uno de estos apartados. No obstante, concretamente en este estudio empírico se ha seguido un mismo esquema planteado en una ficha de análisis de elaboración propia. Dicho esquema está compuesto por una serie de elementos más relevantes que se señalan a continuación:

- Bloque 1: los rasgos del estilo estético del director e identificación de algunos puntos narrativos más significativos de la obra. 
- Bloque 2: está dividido en dos subapartados correspondientes a un estudio de caso del personaje menor de edad protagonista o con papel trascendental en la diégesis:

1. ${ }^{\circ}$ Se contextualiza al individuo en su espacio y su tiempo.

2. ${ }^{\circ}$ Se realiza un análisis de tipo narrativo (contenido) y de su puesta en escena, recogiendo tres ejes principales:

A) Dimensión física: aspectos corporales y vestuario principalmente.

B) Dimensión psicológica: las reacciones de los personajes, sus relaciones, acciones, actuaciones, posible evolución, nivel de autoestima y etnia. Para la motivación en particular, se han seguido las consideraciones de Francia y Mata (1992) que la definen como un conjunto de factores dinámicos que determinan el comportamiento del individuo y para la que trataremos estos cuatro deseos básicos que lo conducen a la acción: seguridad, nueva experiencia, reconocimiento y respuesta afectiva.

C) Dimensión social: no se ahondará en las características del contexto socio histórico, ya que en todas se comparte el período de la dictadura franquista española y los primeros años de la Transición Política, que se exponen en el apartado dedicado a ello, sino en cómo este contexto les afecta de una forma u otra. Precisamente aquí se explorarán también aspectos como sus movimientos: en qué momento del día, en qué espacios, cuál es su cotidianidad, si recibe algún tipo de educación oficial, qué tipo de carencias o hábitos sociales tiene y la posición socioeconómica familiar.

- Bloque 3: en líneas generales aquí se llevará a cabo un análisis detallado sobre la utilización del lenguaje audiovisual, para lo que se describirán algunos aspectos morfológicos y sintácticos más significativos. Con este breve estudio de las estrategias y recursos filmicos se pretende contrastar las distintas visiones y la creatividad de cada director para construir un discurso que recrea un mismo período histórico.

Sin embargo, antes de acometer un análisis de personaje, conviene matizar este concepto. Ciertamente el personaje supone un elemento esencial de la diégesis narrativa que continúa albergando una problemática en su exploración, como consecuencia de la complejidad del concepto y la diversidad de funciones que esta figura adopta en la ficción (Sánchez Navarro, 2006). Aunque para llevar a cabo una aproximación a la figura del personaje sería necesario plantear tres interrogantes: ¿qué es?, ¿de qué está hecho o cuáles son sus ingredientes? Y ¿para qué sirve? (Sánchez Navarro, 2009). En este sentido, el personaje responde a las exigencias de diferentes códigos: político, social, religioso, económico u otros que se encuentran vigentes en el contexto de su creación. No obstante, mientras que algunos teóricos afirman que el personaje 
se integra como un elemento más de la estructura narrativa, otros consideran que supone el reflejo de la visión del mundo de un determinado autor o grupo social. Asimismo un personaje puede ser definido en el ámbito de la sociología como poseedor de una identidad psicológica y moral afín a la de los seres humanos (Galán Fajardo, 2007). Por lo que, a grandes rasgos, en la estructura narrativa clásica algunas variables que intervienen en la base de la creación son: el personaje, la acción y el conflicto, que se entremezclan para construir la organización dramática (Galán Fajardo, 2007). A esto, se podría incorporar también la importancia de los escenarios, como supone la contextualización en el espacio y en el tiempo en los cuales un individuo está integrado (Miguel Borrás, Bermejo Berros y Canga Sosa, 2008). Sin embargo: «no podemos valorar si la estructura es más importante que los personajes, porque la estructura es sus personajes y los personajes son la estructura. Son lo mismo, y uno no puede ser más importante que los otros» (McKee, 1997: 131).

Todas estas significativas aportaciones ponen en evidencia que el personaje supone un elemento de la diégesis narrativa que resulta complejo de explorar ante las dificultades que surgen en su creación, la multitud de pasos a llevar a cabo, los ingredientes de los cuales se conforman sus distintas dimensiones, sus transformaciones y los conceptos abstractos referidos a sus cualidades personales. Además, comprobamos que son diferentes y variopintos los procesos de construcción de personajes y de forma similar sucede con las metodologías de análisis de este concepto que se integra en un filme.

\section{Resultados}

Se han llevado a cabo varias comparativas de los resultados obtenidos, principalmente en relación a las funciones y las actuaciones de los personajes infantiles y adolescentes que se pasan a explicar a continuación de forma detallada:

- Un primer apartado gira en torno a la narrativa. Lo que se pretende identificar aquí son los puntos de conexión que tienen presencia en forma de subtemas que comparten el conjunto del universo que conforma el corpus de nuestro estudio empírico.

—En un segundo apartado, se subdivide el estudio de la dimensión psicológica en base a tres factores: el temperamento, el carácter y la personalidad. Para la exploración de estas cuestiones se utilizarán unas concepciones con las cuales definir en líneas generales sus matices y sus rasgos trascendentales de construcción.

Precisamente los temperamentos han sido tipificados desde épocas ancestrales, como por Hipócrates de Cos (460 a. C-370 a. C). Si bien los rasgos de la construcción de la naturaleza del humor/temperamento son recogidos por Sánchez-Escalonilla (2014) y realmente siguen influyendo de alguna forma en el personaje del 
cine contemporáneo: sanguíneo, colérico, flemático y melancólico. En este sentido, como pone de manifiesto Sánchez-Escalonilla (2014) el tipo de temperamento que se le asigne a un personaje traerá consigo una cierta predestinación en sus actos y en sus reacciones. Así como los aspectos culturales y el estilo de vida, que determinarán su forma de pensar, de hablar y sus inquietudes personales. Aunque obviamente resulta absurdo pretender un estado puro de estos temperamentos en la vida real, e incluso en la ficción contemporánea, ya que los individuos son únicos. Ahora bien, conviene matizar que se puede dar la circunstancia de que un humor en particular destaque como dominante. Por otro lado, las inclinaciones del carácter de introversión/extroversión fueron planteadas por Jung (1964a.b.), quien ahonda en nociones sobre la psicología profunda e incorporó en su metodología conceptos procedentes de otras disciplinas enmarcadas principalmente en el campo de las Humanidades. Para la exploración sobre este matiz psicológico se ha tomado como referencia dos principales inclinaciones: los personajes extrovertidos y los personajes introvertidos. En última instancia, se desarrolla un estudio en base a la personalidad de los individuos objeto de nuestro estudio. Una cuestión abordada precisamente por Morgan Forster y cuyas concepciones conviene recordar, pues son determinadas fundamentalmente por la presentación de un individuo con las características propias de una personalidad redonda, y, por otro lado, aquel personaje construido con rasgos de la personalidad plana (Morgan Forster, 1996).

Aunque antes de llevar a cabo esta exploración conviene recordar la identidad de los protagonistas que conforman el objeto de exploración: grupo de alumnos internos, Juanito, Itziar, Nini, Ferrán y Pepín, Tito, Andrés, Ramón, Juan, Ofelia, Lorenzo, Andreu y Miguel.

Si pasamos a abordar el primer apartado, en cuanto a los subtemas y a las cuestiones que comparten los diferentes universos ficticios en los cuales la figura de la infancia y la adolescencia son representadas, se pueden destacar los siguientes: la utilización de los menores de edad con fines personales de los adultos en Los girasoles ciegos y en Gracias por la propina; la evasión mental de su contexto a través de muñecos, los juguetes o la imaginación en Los años oscuros y El laberinto del Fauno; las ansias de conseguir libertad individual y social en Eres mi héroe y Pa negre; distintas expresiones del miedo en Silencio roto y El laberinto del Fauno; una actitud conformista en Las ratas y Gracias por la propina; los hábitos tóxicos como el alcohol y el tabaco en los entornos de Demonios en el jardín y ;Arriba Hazaña!; y la presencia de la muerte tanto de forma directa como indirecta está presente en el conjunto de la muestra.

Ahora continuamos con el estudio de la dimensión psicológica. Para ello, se aúnan los bloques de análisis de los temperamentos y de las personalidades, en lo que a la representación cinematográfica de los menores de edad se refiere, se ha podido apreciar que viene determinada por la multitud de matices psicológicos que se conjugan en la dimensión psicológica, ya que un mismo individuo infantil y adolescente 
presenta particularidades propias de distintos temperamentos e inclinaciones del carácter, dando lugar a personajes únicos y especiales. Así pues, en lo referido a la personalidad, ciertamente los individuos objeto de la presente exploración pueden concebirse como redondos o complejos. Salvo el personaje de Juan, pues se considera plano, ante la presentación de imposibilidad para expresarse, ya que es restringido por su entorno y revela únicamente temor.

\section{Discusión y conclusiones}

Por último, en este apartado se van a poner de relevancia una serie de consideraciones finales en forma de discusión de resultados obtenidos en la investigación llevada a cabo.

En la narrativa cinematográfica española realizada en la etapa democrática que toma como referencia el contexto de la dictadura franquista los niños y adolescentes se representan ambientados en entornos siempre autoritarios, restrictivos y totalmente normativizados, en los cuales esta violencia adquiere especial relevancia, como se planteó en una de las hipótesis. Si bien el objetivo de esta violencia va enfocado a la opresión y la sumisión de los individuos por parte de los adultos o sujetos que ostentan cierto rol dominador. En este sentido, se ha comprobado que esta violencia se presenta principalmente de forma explícita, concretamente, por citar algunos ejemplos relevantes, sucede así en las ficciones desarrolladas en los entornos de Ofelia, de los hermanos Ferrán y Pepín, de Nini, de Miguel, de Lorenzo y de Juanito. Aunque aquí también se pueden mencionar algunas excepciones, entre las que cabría señalar al grupo de alumnos internos en el centro, pues son éstos quienes la ejercen; el universo de Itziar, en el cual los golpes son representados de forma implícita y con especial énfasis subrayamos el caso de Juan, en cuyo espacio la agresividad es mostrada a través del particular estilo sobreentendido de Montxo Armendáriz. Y, una representación de la violencia más salvaje e inhumana es visualizada en los casos de Nini, porque presencia el asesinato perpetrado por su padre; el turbador caso de Andreu, quien vislumbra el intento de abuso del alcalde a su madre a través de una puerta, unido a las posibles agresiones de su padre dirigidas hacia el hermano de la señora Manubens; y en último lugar, Ofelia, en cuyo entorno la creatividad filmica toma forma para la construcción de su fantasía procedente de los cuentos, conjugada con la muerte y la violencia. Como bien lo denomina Zumalde Arregui (2013) este filme marida la Historia y lo sobrenatural, lo que tiene como resultado un relato con dos historias entrecruzadas o líneas de acción (lo histórico vs. lo fantástico) que transcurren en paralelo, teniendo como fin dos finales superpuestos. Especialmente, este último caso es brutalmente expuesto en la pantalla, pues exhibe unas escenas colmadas de golpes, de cisuras, de desfiguraciones, de agonía, de sacrificios, de sangre y de vísceras. Por lo que se constituye en el único filme en el cual la protagonista adolescente pierde la vida a manos de un adulto sin motivo aparente. 
Precisamente es general y transversal a muchas películas una violencia y una agresividad que van acompañadas de desconfianza y generan un temor permanente en los niños y en los adolescentes, como efectivamente apreciamos que se produce en Ofelia, en Juan, en Itziar y en Ramón. Por este motivo, a los niños y a los adolescentes les supone una desolación tan grave el hecho de convivir en estos entornos de agresividad, que son capaces de matar o arremeter contra quienes tienen alrededor, en un clima de enajenación que les rodea y les vulnera. De esta forma, presentan o imitan unas actitudes similares a lo que observan a su alrededor; así se hace evidente en los casos de Ramón, que se enfrenta contra uno de sus compañeros y en los hermanos Ferrán y Pepín, pues agreden al religioso del centro educativo.

Aparte de ello, resulta también significativo que en la recreación de las características de este contexto socio histórico se pone de manifiesto que la institución eclesiástica jugó un papel importante en la represión de individuos. Esto sucede, por ejemplo, en los escenarios de Andrés y de los alumnos internos. Aunque, como reverso de lo anterior, en algún caso se rompe aquella idea, pues presenta a los religiosos con voluntad transmisora de valores democráticos, presentado así en los casos de Eres mi héroe y Pájaros de papel.

La representación de los menores de edad en los filmes que recrean el contexto de la dictadura franquista realizados en la etapa democrática muestra una significativa variedad de tratamientos argumentales, narrativos y de elementos filmicos, como puede observarse desde los filmes producidos en la primera Transición, y augurando un camino de mayor complejidad temática en la Cinematografía española. En este sentido, se destacan el universo de fantasía propuesto por Guillermo del Toro frente a lo implícito o subyacente, que se deja entrever en el estilo de Montxo Armendáriz o la representación del realismo social presentado en la película de Antonio GiménezRico. Además, resulta significativa, en términos generales, la utilización de un ritmo y un tiempo filmico pausado. Una narrativa lenta aplicada en esta temática en el desarrollo de los filmes examinados y en la cierta parsimonia y ensimismamiento de muchos de personajes infantiles en ejecutar sus acciones, como sucede en los casos de los personajes de Juanito, Itziar, Tito, Andrés y Nini. Adicionalmente, estas características se visualizan mediante la utilización de conectores narrativos, muy comunes en las distintas producciones, entre los cuales se podrían citar: la presencia de la muerte, la utilización de los niños bajo los intereses de los adultos, las mentiras y los insultos.

Mediante el estudio del tratamiento audiovisual de las producciones que conforman nuestro objeto de estudio puede destacarse una serie de elementos trascendentales que entendemos como metáforas o simbolismos recurrentes y que desarrollan un hilo narrativo un personaje infantil. Se observa que los directores y los guionistas desde la Transición recurren habitualmente a estos referentes simbólicos para explicar el universo infantil, a través de los cuales se muestran una serie de deseos, de sentimientos o de necesidades. Podemos destacar los siguientes: los pájaros, 
que representan la añorada libertad de distintas formas, como en figuras de papel representadas en el universo de Miguel y en los diálogos desarrollados entre Andreu y Tísic; el árbol, un elemento de la naturaleza que acompaña a las únicas protagonistas menores de edad femeninas como son Ofelia e Itziar; obviamente el camión de juguete y en general el mundo del juego supone un referente primordial que contribuye a la formación de la amistad en los niños y las niñas, como actividad que despierta vínculos afectivos, presente en los universos de Andrés, de Ramón, de Tito y de Ofelia. Además, la mirada es concebida como una metáfora del proceso de aprendizaje y como fuente de conocimiento, que funciona como eje principal en el desarrollo de la trama presentada en los universos de Andreu, de Juanito, de Nini, de Ramón y de Itziar. En último lugar, se pueden citar evidentemente las cruces, pues funcionan como elemento significativo que subraya el establecimiento de una ideología religiosa preponderante como era considerado el catolicismo: de forma implícita, por ejemplo, en una de las ventanas del colegio de Lorenzo y de forma explícita en otros filmes, entre los que cabría mencionar los universos vitales de Itziar, de Andreu, de Ramón, de Andrés, de los hermanos Ferrán y Pepín y de Nini.

Significativamente uno de los códigos sonoros predominantes presentes en el conjunto de las producciones examinadas son los disparos, asociados metafórica y realmente a la violencia ejercida durante la dictadura. Disparos ejecutados por los adultos en las proximidades de los niños y de los adolescentes. Bajo el mismo peso, se remarcan también la importancia de los silencios, especialmente durante las noches, pues enfatizan la soledad y la ausencia de libertad de expresión que los rodean.

Entre los códigos visuales especialmente relevantes que se observan, se encuentran las líneas verticales, que representan ese equilibrio social que se pretende alcanzar a través del establecimiento social y familiar del ideario nacional católico. Ello se representa en forma de elementos decorativos en los escenarios y adheridos como detalles en los vestuarios, como se aprecia en los pijamas del grupo de alumnos internos en el centro, de Lorenzo y de Andreu. Y estrechamente relacionado con el escenario educativo, pues la regla funcionaría como elemento represor, ya que aparece por ejemplo en el entorno de Andrés. Igualmente, se revela importante la presencia de las formas circulares, que ponen de relieve la incuestionable evolución psicológica que padecen gran parte de los protagonistas infantiles y adolescentes que conforman este universo de estudio. Posiblemente como consecuencia de sus observaciones, de su aprendizaje académico y de la influencia de su contexto.

En lo que a elementos sintácticos se refiere, y principalmente respecto a la angulación, se han encontrado algunas particularidades que consideramos significativas. Conviene aclarar puntualmente que la utilización de la perspectiva de cámara en picado se suele utilizar para mostrar la debilidad o fragilidad de un personaje, mientras que el contrapicado a menudo se viene exponiendo para el engrandecimiento de su figura. Sin embargo, estas connotaciones se rompen en algunos filmes que hemos es- 
tudiado, ya que advertimos que se han podido utilizar con otra intencionalidad. En este sentido, hemos encontrado que hacia el final de Eres mi héroe, justo en los primeros años de la Transición política española, cuando se van dando pasos aún vacilantes hacia el sistema democrático, se puede apreciar un encuadre aberrante de un maestro del centro. Personaje que precisamente venía actuando como defensor del sistema dictatorial, pues desde el inicio del relato su figura de autoridad viene siendo representada a través de contrapicados. Por otro lado, cabría citar el filme Pájaros de papel, en el cual se puede apreciar que, durante una conversación desarrollada en el emplazamiento de unas escaleras, los dos Guardias Civiles principales de la película son mostrados a través de una angulación en picado, como posible intento de representar cierta debilidad en su autoridad. Cuando el poder de estos venían siendo representados mediante la perspectiva en contrapicado respecto a los trabajadores de la obra teatral en la cual se inmiscuyen.

La presencia y la utilización del color ofrecen en estos filmes una clara voluntad emocional y psicológica. Principalmente se observa de forma general en forma de filtros de la cámara en tonalidades azul y verde. Justamente éstos funcionan como metáfora que encarna la frialdad y la insensibilidad del universo adulto en estos contextos totalitarios, especialmente visibles en los espacios de Ofelia, de Itziar y de Andreu. Es significativa también la coloración de la vestimenta de los menores de edad. En este sentido cabría destacar el rojo, que recuerda a la sangre derramada por las víctimas que perdieron la vida en el contexto de represión; el blanco, que refleja la inocencia de la etapa infantil; el negro, que representa el luto y el dolor; el gris, que muestra apagamiento y cierta neutralidad o apaciguamiento y sumisión; o los tonos ocres como color propio de la sequía y la melancolía del otoño. Todos ellos están vinculados a las peripecias narrativas de sus protagonistas. Aunque también destacamos dos filmes en los cuales se presentan distintos matices y tonalidades más vibrantes y atrayentes, como sucede con el verde y el naranja, presentes en la indumentaria y en los complementos de Ofelia y de Ramón. Asimismo, subrayamos la importancia de la yuxtaposición de estos sugerentes colores, pues se presentan en algunas secuencias trascendentales compartidas en la ficcionalización de los tebeos que toman vida en Eres mi héroe y en El florido pensil. Lo que entendemos que puede ser influencia del cine de los inicios de la Democracia.

En la representación del contexto histórico de los filmes descritos resulta obvia la privación de una facultad esencial del ser humano como es la libertad. En este sentido, se observa que algunos personajes intentan acercarse a la misma a través del proceso de evadirse mentalmente y también mediante el descubrimiento de la formación y el conocimiento escondido en el interior de los libros y de los cuentos, como hacen Ofelia, Andrés, Andreu y Lorenzo. Además, en algunos universos ficcionales de estas películas se aprecian elementos que funcionan como figuras alegóricas de esta anhelada libertad, como sucede con la bicicleta de Juan, el camión de juguete de Tito, el tren que resuena en el exterior del centro interno e incluso el que toma Miguel para partir hacia Portugal. 
Un aspecto destacado que hallamos en la mayoría de los personajes protagonistas infantiles analizados viene determinado por la ausencia de la identidad individual. Ello se relaciona, en cierta medida, dadas las tramas que muchas de ellas desarrollan, con un posible intento de suprimir o posiblemente de ignorar sus antecedentes familiares, ocultos al conocimiento del propio menor de edad e incluso a los propios espectadores de la obra. Aunque puede también interpretarse como un intento de los guionistas de manifestar de esta forma la anulación de este reconocimiento que se está otorgando a quienes reclaman su derecho a la recuperación de sus raíces. Precisamente restando importancia y prescindiendo del nombre familiar con el que se distinguen las personas: los apellidos. Asimismo, también hallamos significativo el hecho de encontrarnos exclusivamente con dos personajes protagonistas menores de edad de género femenino. Lo que puede entenderse, aún durante la etapa democrática, como una muestra de ausencia de interés cinematográfico hacia su presencia en la gran pantalla o al menos de forma secundaria. Relegando su representación hacia un segundo plano, como también es el modo en que ha sido tratada la figura femenina durante el contexto histórico que se toma como referencia.

Para terminar, se puede afirmar que, en la investigación desarrollada, la representación de los adultos que se relacionan con los menores, integrados en los filmes examinados, y teniendo en cuenta la yuxtaposición de factores que intervienen en el proceso de construcción de un personaje, continúa anclada la mostración del maniqueísmo, las personalidades planas y los estereotipos sociales. Esto puede observarse, por ejemplo, en los educadores presentes en El florido pensil y en Los girasoles ciegos. En cambio, en lo que a la representación cinematográfica de los menores de edad se refiere, se ha apreciado un aspecto distinto. Un aspecto que viene determinado por la multitud de matices psicológicos que se conjugan en la dimensión psicológica, pues un mismo individuo infantil y adolescente presenta particularidades propias de distintos temperamentos e inclinaciones del carácter, dando lugar a personajes únicos y originales. Así, en lo referente a la personalidad, ciertamente los individuos menores de edad objeto de la presente exploración pueden concebirse como complejos y redondos.

Finalmente, en el cine español realizado en la etapa democrática e inspirado en este contexto de dictadura, los adultos causan perjuicios en la inocencia de los pequeños, haciendo uso del odio, la intolerancia, la discriminación escolar que aparece principalmente en los entornos en los cuales la asistencia al colegio es más regular, como se aprecia en El florido pensil, Los años oscuros, ¡Arriba Hazaña! y Los girasoles ciegos, así como la ruptura de ilusiones pretendidas en la infancia. Precisamente esto es lo que encontramos en Ofelia, pues fulminan su idea de la existencia de los cuentos y los personajes sobrenaturales; Ramón, Juan, Andreu y Lorenzo que conviven entre el miedo social de sus familias y el fanatismo ideológico/religioso de gran parte de los adultos que integran su entorno. Igualmente, la familia de Itziar rompe su ilusión 
de dedicarse al baile y a Andrés le recuerdan la prohibición de no llevar a cabo acciones que conllevan distracción, pues supone un pecado. Así pues, la inocencia, la ilusión y la alegría propia de las etapas infantil y adolescente tienen escasa presencia en los protagonistas de las ficciones examinadas que recrean este período histórico.

\section{Referencias bibliográficas}

Anguera Argilaga, T. (1986). La investigación cualitativa. Educar (10), 23-50. Recuperado de https://dialnet.unirioja.es/servlet/articulo?codigo $=5570238$

Asenjo García, F. (1998). Índice del cine español. Madrid: Ediciones JC Monteleón.

Aumont, J. y Michel, M. (1990). Análisis del film. Barcelona: Paidós.

De Felipe Aullé y Gómez, I. (2012). Miedos en transición: el cine fantástico español en los años de plomo", actas del III congrés internacional de la associació espanyola d'investigació de la comunicació (pp. 1-15), (Tarragona, Universitat Rovira i Virgili).

Francia, A. y Mata, J. (1992). Dinámica y técnicas de grupos. Madrid: Editorial CCS.

Galán Fajardo, E. (2007). Fundamentos básicos en la construcción del personaje para medios audiovisuales. Enlaces: Revista del CES Felipe II, (7), 1-11. Recuperado de https:// dialnet.unirioja.es/servlet/articulo?codigo $=2362979$

Gómez López-Quiñones, A. (2009). Hadas, maquis y niños sin escuela: la infancia romántica y la Guerra Civil en El laberinto del Fauno, Vanderbilt e-Journal of luso-hispanic studies, 5, 73-92. Recuperado de https://ejournals.library.vanderbilt.edu/index.php/ lusohispanic/article/view/3225

Jung, C. G. (1964a). Tipos psicológicos I. Buenos Aires: Editorial Sudamericana.

Jung, C. G. (1964b). Tipos psicológicos II. Buenos Aires: Editorial Sudamericana.

Lincoln, Y. S. y Guba, E. (1985). Naturalistic inquirí. Londres: Sage Publications.

McKee, R. (1997). El guion. Sustancia, estructura, estilo y principios de la escritura de guiones. Barcelona: lbaminus.

Martí Saldes, M. (2005). La investigación empírica aplicada a la producción de ficción televisiva: propuesta de metodologías experimentales. Formats: Revista de comunicació audiovisual (4), 1-10. Recuperado de https://dialnet.unirioja.es/servlet/ articulo? codigo $=2194353$

Martínez-Salgado, C. (2012). El muestreo en investigación cualitativa. Principios básicos y algunas controversias. Ciênc. Saúde coletiva, 17 (3), 613-619. Recuperado de http:// www.scielo.br/pdf/csc/v17n3/v17n3a06.pdf

Metz, C. (1972). Ensayos sobre la significación del cine. Buenos Aires: Tiempo contemporáneo.

Miguel Borrás, M., Bermejo Berros, J. y Canga Sosa, M. (2008). (coords.). Siete miradas, una misma luz. Teoría y análisis cinematográfico. Valladolid: Secretariado de Publicaciones e intercambio editorial.

Morgan Forster, E. (1996). Personajes planos y personajes redondos. En Enric Sullà (coord), Teoría de la novela: antología de textos del siglo XX (pp. 35-37). Barcelona: Crítica. 
Ocón Domingo, J. (2006). Normativa internacional de protección de la infancia. Cuadernos de trabajo social (19), 113-131. Recuperado de https://dialnet.unirioja.es/servlet/ articulo? codigo $=2575002$

Pantoja Chaves, A. (2011). El franquismo a través del cine de la transición y la democracia. Un cruce de visiones entre la modernidad y la memoria. O Olho da história (17), 1-14. Recuperado de http://oolhodahistoria.ufba.br/wp-content/uploads/2016/03/ antoniop.pdf

Perceval, J. M. y Fornieles Alcaraz, J. (2008). Confucio contra Sócrates: la perversa relación entre la investigación y la acreditación. Anàlisi (36), 213-224. Recuperado de https:// dialnet.unirioja.es/servlet/articulo?codigo $=5882099$

Sánchez Escalonilla, A. (2014). Estrategias de guion cinematográfico. Barcelona: Ariel.

Sánchez Navarro, J. (2006). Narrativa audiovisual. Barcelona: UOC.

Yela Fernández, O. R. (2013). Infancias vulneradas en las guerras de España y Guatemala. El futuro del pasado (4), 207-226. Recuperado de https://dialnet.unirioja.es/servlet/ articulo? codigo $=4260538$

Zumalde Arregui, I. (2011). La experiencia fímica. Cine, pensamiento y emoción. Madrid: Cátedra.

Zumalde Arregui, I. (2013). El laberíntico caso del Fauno. A propósito de la identidad nacional de las películas. ZER Revista de estudios de comunicación, 18 (34), 195-209. Recuperado de http://www.ehu.eus/ojs/index.php/Zer/article/view/10657/9895

\section{Material AUdiovisuAL}

- ¡Arriba Hazaña! (José María Gutiérrez Santos, 1978)

- Demonios en el jardín (Manuel Gutiérrez Aragón, 1982)

- El florido pensil (Juan José Porto, 2002)

- El laberinto del Fauno (Guillermo del Toro, 2006)

- El portero (Gonzalo Suárez, 2000)

- Eres mi héroe (Antonio Cuadri, 2003)

- Gracias por la propina (Francesc Bellmunt, 1997)

- Las ratas (Antonio Giménez-Rico, 1997)

- Los años oscuros (Arantxa Lazcano, 1993)

- Los girasoles ciegos (José Luís Cuerda, 2008)

- Silencio roto (Montxo Armendáriz, 2004)

- Pájaros de papel (Emilio Aragón, 2010)

- Pa negre (Agustí Villaronga, 2010) 